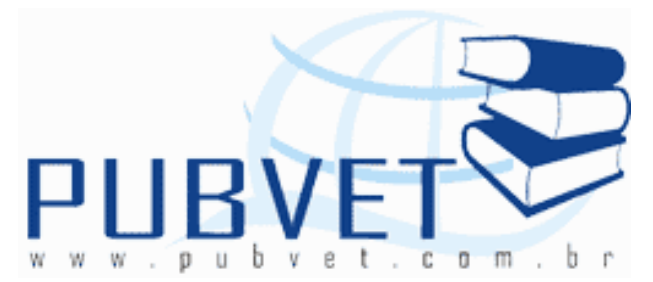

PUBVET, Publicações em Medicina Veterinária e Zootecnia.

\title{
Ocorrência de Tetrameres spp em frango caipira Gallus Gallus Domestics
}

Humberto Eustáquio Coelho ${ }^{1}$, Tatiane Furtado de Carvalho ${ }^{2}$, Hélio Alberto ${ }^{3}$, Cláudio Henrique Gonçalves Barbosa², Karina Danielle Cobo Silva ${ }^{4}$, Carla Cunha Locce ${ }^{4}$, Jéssica Oliveira Felice ${ }^{4}$, Flavia Maria Esteves Machado ${ }^{1}$

1-Professor na Universidade de Uberaba, 2-Residente de Patologia Animal na Universidade de Uberaba, 3-Técnico do Laboratório de Anatomia Patológica do Hospital Veterinário de Uberaba (HVU),

4- Acadêmico do curso de Medicina Veterinária da Universidade de Uberaba

\section{Resumo}

A verminose é uma enfermidade que provoca anemia e depalperação. O Tretameres americana por se localizar no proventrículo ocasiona proventriculite com edema da parede do proventrículo e hipotrofia muscular. O presente trabalho relata um caso de verminose em aves domésticas, ocorridas na região de Uberaba - MG.

Palavras-chave: Verminose, Proventriculite e Aves. 


\section{Occurrence of Tetrameres spp in organic chicken Gallus Gallus Domestics}

\section{Summary}

The worms is a disease that causes anemia and weakened. The Tetrameres amercan as it is located in proventriculus proventriculitis causes edema of the wall proventriculus and muscle atrophy. This paper reports cases of worms in poultry occurred in the region of Uberaba - MG.

Keywords: Worms, and birds proventriculitis.

\section{INTRODUÇÃO}

Os nematóides são vermes de corpo cilíndrico, comprido, afinado nas extremidades. Eles são os parasitas mais frequentemente encontrados nas criações de aves (REIS, 1964).

A espécie do gênero Tetrameres, tem um ciclo heteroxêmico, do qual as aves são as hospedeiras definitivas (SILVA et al., 2005). Parte da evolução dos Tetrameres se passa no organismo de certos invertebrados (gafanhotos, baratas, crustáceos), comendo esses animais é que as aves se infestam (REIS, 1964).

Poucos são os parasitos que habitam o proventrículo. Alguns nematóides (Tetrameres spp) vivem das secreções das glândulas do órgão e constantemente provocam proventriculites (COELHO, 2006). Penetram na mucosa ou nas glândulas do proventrículo, causando úlceras, hemorragias, edema e obstruções. A luz das glândulas do proventrículo apresenta-se dilatada, em consequência da descamação celular, que evolui para atrofia por degeneração do tecido glandular. Um cisto é formado em torno da glândula (FORTES, 1997).

Os parasitas apresentam dimorfismo sexual, os machos são pálidos, delgados, de apenas $6 \mathrm{~mm}$ de comprimento e com cutículas espinhosas, vivem na superfície mucosa do proventrículo. Enquanto as fêmeas, vermelhas-vivas, 
COELHO, H.E. et al. Ocorrência de Tetrameres spp em frango caipira Gallus Gallus Domestics. PUBVET, Londrina, V. 5, N. 24, Ed. 171, Art. 1153, 2011.

quase esféricas e com diâmetro de aproximadamente $5 \mathrm{~mm}$, ficam no fundo das glândulas mucosas (UHQUHAR et al., 1998).

As fêmeas são hematófagas e podem causar anemia, bem como erosão local. As infestações maciças podem ser fatais em pintinhos, mas estes nematóides frequentemente estão presentes apenas em quantidades moderadas e é bem tolerado (URQUHAR et al., 1998).

Os sinais clínicos incluem diarréia, anemia e emagrecimento (MARTINS, 2009).

\section{RELATO DE CASO}

Um total de 40 frangos caipiras de um criatório da região de Uberaba do estado de Minas Gerais estava apresentando sinais clínicos que incluíam emagrecimento. Uma ave doente foi enviada ao Laboratório de Patologia Animal do Hospital Veterinário de Uberaba (HVU), que posteriormente foi submetida à eutanásia e necropsiada. Ao exame físico observou que a mesma apresentava anêmica, magra e com hipotrofia muscular.

Na necropsia, de forma geral, foram observadas presença de hematomas e parede edemaciada no proventrículo, além da presença de Tetrameres spp (Fig. 01 e 02). 


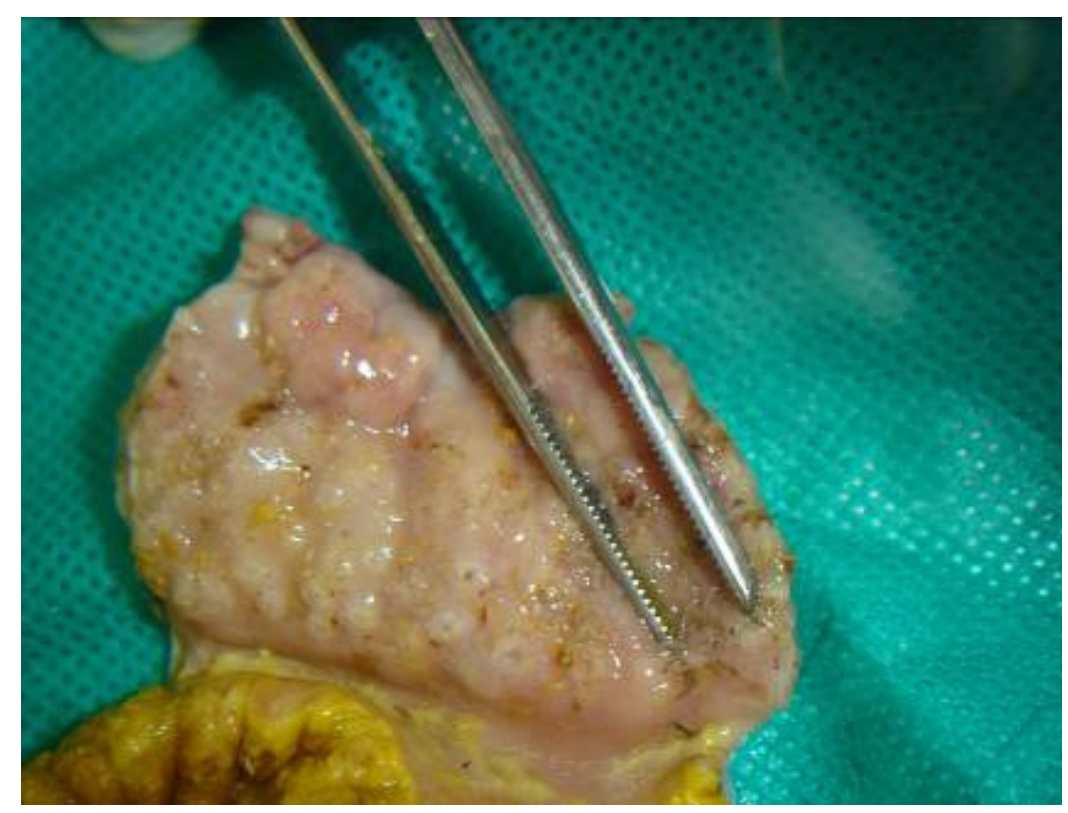

Figura 01- Proventrículo de uma ave. Observar a parede edemaciada do proventrículo, associada à presença dos parasitas.

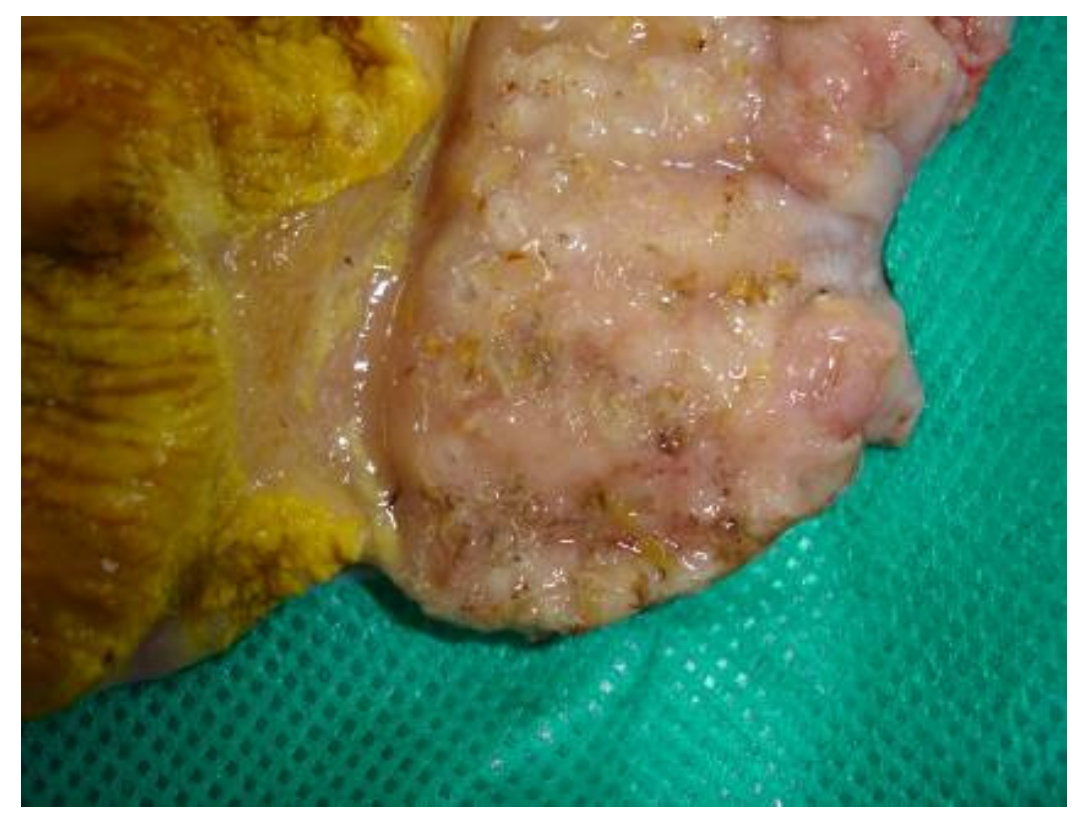

Figura 02- Proventrículo de uma ave. Evidenciando os parasitas na mucosa do proventrículo. 
COELHO, H.E. et al. Ocorrência de Tetrameres spp em frango caipira Gallus Gallus Domestics. PUBVET, Londrina, V. 5, N. 24, Ed. 171, Art. 1153, 2011.

\section{DISCUSSÃo}

A infestação por Tetrameres causa uma proventriculite, MACHADO et al. (2006) relatam que, seja devido as fêmeas desses parasitas estarem profundamente incluídas nas glândulas do proventrículo, e os machos na superfície da mucosa.

Os sinais clínicos e as lesões observadas na ave necropsiada neste relato são semelhantes aqueles descritos por MARTINS (2009).

Como os animais são provenientes de criação doméstica é comum que tenham contato com os hospedeiros do Tetrameres spp, os autores RUPLEY (1999), MARIETTO GONÇALVES et al. (2006), observaram que as infecções parasitárias ocorrem em aves com acesso ao chão e nas aves livres no ambiente, que estão expostas a aves silvestres ou aos seus excrementos, e são intimamente relacionadas aos alimentos e hábitos dos animais.

De acordo com MACHADO et al. (2006), há possibilidade de uma infecção de maneira passiva, tanto no ambiente aquático como no ambiente terrestre, uma vez que insetos, crustáceos, poderiam abrigar tais formas infectantes, e estes animais também servem de alimento ás aves.

Assim como nessa ave foi encontrado a presença de Tetrameres spp, GIOVANNONI e KUBIAK (2001), também observaram esses nematódeos em Gallus domesticus.

A criação desses animais em ambientes com área restrita, induz ao stress, o que é relatado por RUPLEY (1999), MARIETTO GONÇALVES et al. (2006), devido isso diminui a capacidade imunológica e propicia o surgimento das parasitoses.

\section{CONCLUSÃO}

A preocupação com a ocorrência de Tetrameres spp em criações de frangos caipiras é relevante, pois a doença causa elevada perda econômica devido à redução do peso e mortalidade. Medidas de controle e profilaxia 
COELHO, H.E. et al. Ocorrência de Tetrameres spp em frango caipira Gallus Gallus Domestics. PUBVET, Londrina, V. 5, N. 24, Ed. 171, Art. 1153, 2011.

devem ser adotadas, principalmente se houver contato das aves do plantel com aves de origem desconhecidas. É muito importante ressaltar que a infestação de Tetrameres esta associada à proventriculite.

\section{REFERÊNCIAS BIBLIOGRÁFICAS}

COELHO, H. E. Patologia das aves. $1^{\text {a }}$ ed. São Paulo: Tecmedd, 2006.

FORTES E. Parasitologia veterinária. 3a ed. São Paulo: Ínconr, 392 p.,1997.

GIOVANNONI, M.; KUBIAK, G. V. L. Fauna parasitológica paranaense. IV. Lista prévia da ocorrência de helmintos em animais domésticos. Brazilian Archives of Biology and Tecnology, v.2, n.4, p. 289-292, 2001.

MACHADO, A. C. R.; LIMA, O. M.; ARAÚJO, J. L. B. Helmintos parasitos em aves anseriformes que ocorrem em Goiás. v.35, n. 3, p. 185-198. set.-dez. 2006. Disponível em: < http://www.revistas.ufg.br/index.php/iptsp/article/viewFile/1879/1792> Acesso em 01 jan. 2010.

MARIETTO GONÇALVES, G. A.; MARTINS, T. F.; LIMA, E. T.; LOPES, R. S.; ANDREATTI FILHO, R. L. Prevalência de endoparasitas em amostras fecais de aves silvestres e exóticas examinadas no Laboratório de Ornitopatologia e no Laboratório e Enfermidades Parasitárias da FMVZ-UNESP/Botucatu-SP. In: XV Congresso Paulista de Zoológicos, 2006, São Pedro-SP. Anais do XV Congresso Paulista de Zoológicos, 2006.

REIS, J. Doença das aves. 6a ed. São Paulo: Melhoramentos, 1964.

RUPLEY, A. E. Manual de clínica aviária. São Paulo: Roca, p. 501-502, 1999.

SILVA, R. J.; OLIVEIRA-SEQUEIRA, T. C. G.; GURGEL, C. C. Arq. Bras. Med. Vet. Zootec. v. 57, n.4, Belo Horizonte, Aug.2005 - Occurrence of Tetrameres confusa (Nematoda, Tetrameridae) in Ara ararauna (Psittacidae). Disponível em: http://www.scielo.br/scielo.php?pid=S0102-09352005000400022\&script=sci arttext Acesso em 05 jan. 2010.

URQHART, G. M.; ARMOUR J.; DUNCAN J. L.; JENNINGS F. W. Parasitologia veterinária. 2a ed. Rio de Janeiro: Guanabara Koogan, 74p.,1998. 